\title{
Enlargement, Association, Accession - A Normative Account of Membership in a Union of States
}

By Joseph Lacey and Rainer Bauböck

Published in Journal of European Integration, 2017, Volume 39, 2017, Issue 5

http://dx.doi.org/10.1080/07036337.2017.1327523

Post-print version

\begin{abstract}
This paper deals with the legitimacy of the EU's external borders and the decision-making rules for changing them. First, while the EU should not indefinitely expand, we can identify no normative grounds for precluding in advance any liberal democratic nation-states from participation in the European project. Second, for those countries having more or less thick legal ties with the EU, or who are otherwise substantially affected by European decisionmaking, we argue for the institutionalisation of flexible deliberative communities. For closely associated countries, we argue that the EU has special duties in opening the door to membership. Third, we address the legitimacy of the EU's decision-making procedures for deciding on accession candidates and creating association agreements with non-member states. Here we defend the EU's current unanimity requirement for the former and its supermajoritarian decision rules for the latter. Finally, we suggest that nationalism is the primary obstacle to the achievement of just inclusion outcomes for non-member states.
\end{abstract}




\section{Introduction}

This paper deals with what is perhaps the paradigmatic case of political boundaries, namely the external borders marking out the territory within which a political community is established. From a longue durée view of European history, border disputes and changing territorial compositions are at least as frequent as cases with relatively stable and uncontested borders. Yet the EU is still a unique case in this regard. Unlike modern democratic states, which tend to assume constitutionally the fixity of their borders, the pliability of the EU's borders is constitutionalised through secession and accession clauses. While two other papers in this volume (Lord and Shaw) investigate the issue of secession, this contribution will dedicate itself to issues of legitimacy pertaining to accession.

We begin with the most general question, which is underexplored from a normative perspective, namely whether or not there are legitimate limits to European expansion. While we argue that the EU should not indefinitely expand, the available criteria for precluding in advance expansion beyond the European continent are ultimately not convincing. So long as a country shares a civic commitment to liberal democratic values, we can identify no normative grounds for precluding in advance any nation-states from participation in the European project. The next section deals with somewhat more specific questions that have received even less attention from normative theory, that is, what the EU owes those countries with which it has relations short of membership by way of inclusion in its decision-making process. For those countries having more or less thick legal ties with the EU, or who are otherwise substantially affected by European decision-making, we argue for the institutionalisation of a flexible deliberative community based on ex ante consultation and ex post justification. When it comes to those associated countries who are more densely entwined with the European legal 
architecture, we argue that the EU has special duties in opening the door to membership. Following this, we address the legitimacy of the EU's decision-making procedures for deciding on accession candidates and creating association agreements with non-member states. Here we defend the EU's current unanimity requirement for the former and its supermajoritarian decision rules for the latter. Although this does not guarantee just outcomes for accession candidates in particular, such concerns cannot trump the right of each member state to have a final say over the composition of the European polity. Finally, we suggest that nationalism is the primary obstacle to the achievement of just inclusion outcomes for non-member states. The pursuit of an active consensus among the peoples of Europe by national and European elites is both normatively and prudentially required.

\section{The Normativity of EU Enlargement}

Four main types of argument are available to justify restricting membership of a political community. One is numeric and claims that certain values are compromised by letting too many into the political community. Another is geographic and suggests that there is something special about the proximity of agents to one another that justifies an exclusive scheme of territorial consolidation. A third argument prioritises political values, limiting valid membership applications to those that share the political community's civic self-understanding. Finally, there is an argument for the value of cultural affinity as the basis of political membership. While these are familiar arguments when it comes to membership of individuals as citizens of democratic states, they need to be reconsidered for state membership in a union of states. The primary question to be addressed in this section relates to the legitimate bases of EU membership restrictions.

The main debate surrounding this issue has largely focused on a version of the numerical argument concerning the extent to which there may be a saturation point for the EU's 
'integration capacity', that is, a point at which any further expansion would jeopardise the potential for deeper integration projects as well as the overall effectiveness of the EU as a political system. Such a debate was triggered by the fear of overexpansion in light of the accession of 12 new states between 2004 and 2007. The debate was at least provisionally laid to rest by the Commission's refusal to think of integration capacity in absolute terms by specifying in advance some definite numerical range of states that the EU cannot theoretically or practically extend beyond. Instead, the Commission (2006: 17) insisted that the EU's integration capacity should be considered changeable over time and highly dependent on both the particular profile of the prospective member state(s) and the institutional or political circumstances in which the EU finds itself at the relevant moment.

This perspective has been largely vindicated in practice, as deepening and widening have typically gone hand in hand throughout the history of European integration. As one set of authors argue, while enlargement may produce more gridlock over the short-term, a longerterm perspective demonstrates that a greater number of member states 'produces functional pressures for institutional reform that eventually facilitate deepening' (Kelemen, Menon and Slapin 2014). Meanwhile, there are numerous methods for reducing gridlock in a larger Union. One is the formalisation of differentiated integration in the EU, such that some member states can pursue integration projects without others on-board under certain well-specified conditions (see Bellamy and Kröger in this volume). Another would be to follow some of the variously reasoned recommendations for relegating large amounts of primary law to the status of secondary law, such that only the most important "constitutional essentials" require unanimity in order to be modified (Grimm 2015, Scharpf 2015, Lacey 2017: 229-30).

This refusal to put numerical limits on EU membership is nevertheless framed by the assumption that some or all of the other available arguments justify limiting EU enlargement in some way. The basis for this assumption is outlined by Article 49 of the Treaty on European 
Union (TEU), which allows any 'European state' committed to liberal democratic values to apply for membership of the Union. This paper will not question the validity of the argument for shared political values that restrict EU membership to liberal democratic states. The normative case for this kind of restriction has been well made (e.g. Cheneval 2011). Most importantly, to the extent that the EU legislates for all European citizens, the only way of ensuring equality between them is if they can be guaranteed a similar set of liberal democratic rights wherever they reside or decide to move within the Union's territory. What this section will question, however, is the legitimacy of limiting EU membership to "European" states. This restriction cannot rely on an argument from political values because there are many nonEuropean states that hold similar civic values. It therefore must draw its normative resources from elsewhere.

What counts as a European state is not specified in the Treaties. Documents from the Parliamentary Assembly of the Council of Europe (CoE) (especially 1992), aiming to draw firm borders around the potential members of this organisation, are generally used as a proxy for determining the limits of potential EU membership (Emerson, Aydin, De Clerck-Sachsse et al. 2006: 12; Karakas 2013: 1059). According to these documents: 'Only states whose territory lies wholly or partly in Europe, and whose culture is closely linked with European culture, should be able to request membership of the organisation'. In effect, by proxy, the Council of Europe provides us with two necessary conditions for membership applications to the EU: cultural and geographic. In a rare comment on Article 49 TEU, the Commission (2006: 18) appears to endorse a formula of this kind when it states: 'The term "European" combines geographical, historical and cultural elements which all contribute to European identity'.

Is it possible to construct good normative bases for either of these criteria? Although the meaning of "culture" is not defined in the CoE documents or by the Commission, this requirement would appear to echo the sentiment of liberal nationalists that there is a value in 
sharing political space with those who share a cultural affinity with each other and, furthermore, that this value is important enough to serve as a criterion for membership in political organisations (e.g. Miller 1995, Kymlicka 2001). Indeed, analysis of statements by European elites in the years leading up to the Eastern enlargement demonstrates that appeals to a shared European identity played a prominent role in attempting to convince member states of a duty to expand towards certain culturally proximate countries (Sjursen 2002). One obvious problem with this criterion is that it is far more difficult to identify what is distinctive about a continental culture that is supposed to encompass all prospective European states than it is to identify salient markers of an exclusive national culture. There is certainly no common language available to unify a European culture, while the CoE Legal Affairs Committee (1992) rightly cautions against deploying common religious or philosophical traditions as a distinctive marker of European identity, given the fact that most European states are now multicultural societies.

Despite the Commission's rare comment above, the Treaties are very careful about not positing the existence of a European culture, precisely for this reason. And the EU asserts that it is founded upon the purely civic values of liberal democracy (Article 2 TEU). Indeed, the success of European integration has heretofore been predicated on its normative commitment to a) utilising civic principles as a means of uniting different cultures and b) seeking to minimise the threat of European integration to member state cultures by adopting policies to protect and promote the diversity of national and local cultures. By placing cultural requirements on membership, the EU would be affirming the existence of a common culture whose presumed absence is supposed to be catered for by the shared endorsement of civic values. In effect, further to the difficulty of defining a European culture, the EU would not be consistent with its own normative standards if it were to emphasize culture as a basis for membership. 
If culture is not promising as a normative criterion for restricting EU membership, the geographic criterion may be more appealing. Jeremy Waldron (2011) presents what he calls the 'proximity principle' as a civic principle of political community formation that justifies territorial consolidation. Contrary to liberal nationalists, Waldron claims that it is not affinity between people but prospective enmity that should be the basis of political community formation. Following Hobbes' and Kant's respective reasoning behind the proximity principle, he claims that it is prudent from the perspective of self-preservation and a moral duty from the perspective of preventing harm to others that likely enemies make allies of one another under the guarantees and constraints of binding law. For all three authors, it is the proximity of individuals to one another that is the primary determinant of enmity as it is neighbours who are most likely to conflict in the struggle for resources. Although Waldron frames his discussion of the proximity principle as a civic justification for the nation-state, it may be also valid on the international stage. Indeed, the rational and moral logic animating the proximity principle seem to have been present when the European Communities were initially founded. To make further war impossible in Europe, the idea was to integrate the continent. For this reason, it was seen as essential that Europe's greatest historical enemies, neighbours France and Germany, would be at the heart of European integration.

Prospective enmity is not, however, the only relevant normative feature of geographic proximity. Indeed, the very idea of political community itself entails more than a commitment to internal peace, involving all members in open-ended collective projects, the nature of which is ideally determined through a democratic process. Within the European context, the promise of socio-economic progress for both the acceding parties and the EU as a whole have been present if not predominant in every round of accession to the EU beyond its original six founding members. This argument can be further supported by a functional reason that 
contiguity of EU territory helps to facilitate the exercise of the four freedoms and the creation of a seamless area of "freedom, security and justice".

Apart from potential and historic enmity and prospects of future co-development, a third reason underpinning proximity-based preferences for membership is special vulnerability. Because one's actions are most likely to negatively affect those in the vicinity, especially weaker or more vulnerable parties, it stands to reason that there may be specific duties arising out of this reality. In particular, those who pursue the advantages of international integration on a regional basis may be simultaneously disadvantaging other states within the wider region and therefore owe the accession applications of these states priority in joining the regional organisation so long as they meet the conditions of membership. By allowing all European states to apply for membership, the EU is in an important respect taking its duty to neighbouring countries seriously.

However, there are three main reasons why this duty cannot on its own serve as an adequate criterion for placing restrictions on European expansion. First, it does not explain why European states like Iceland or (semi-European states like Turkey) should be prioritised in this regard over non-European yet nevertheless geographically proximal states like Morocco or Israel for example (Nicolaïdis 2014: 238). Second, there is nothing self-limiting about this duty as previously distant states may soon become close neighbours as borders expand. Third, to the extent that a regional union is fulfilling its duties to neighbours by way of prioritising their accession requests, potentially even offering forms of assistance so that they can meet the standards of accession, there appear to be no further normative consideration relating to geographic proximity that would mandate against the regional union expanding beyond its neighbours.

Although geographic and numeric criteria have some normative relevance - the one establishing a priority for enlargement to neighbours and the other recognising a possible trade- 
off between integration and enlargement that can be in principle resolved through differentiated integration or constitutional tinkering - it would appear that there is no criterion that justifiably restricts EU membership beyond the requirement that all applicants share liberal democratic values. Nevertheless, there is another kind of numeric argument available that has not to do with the EU's integration capacity but rather the respective freedom of individuals and states.

According to this argument, social relations governed at the global level would open up both individuals and states to domination by eliminating the possibility of exit from the singular world political community. Effectively, individuals who reasonably disagree with or feel discriminated by global rules will be unable to move to an alternative political community where the laws may be more agreeable. When it comes to states, the march towards a global union has the potential to undermine self-determination as the power imbalances created by the majority within a world union and those outside of it would engender conditions of domination of the former over the latter. Such an arrangement would likely lead to near irresistible incentives for hold-out states to join the union, while similarly eliminating the realistic prospect of regaining independence through secession. What is required of any regional union is therefore that its borders preserve conditions for horizontal plurality of regional unions on a global scale. This sets the maximum membership at $\mathrm{N}-\mathrm{n}$, with $\mathrm{n}$ being the minimum number from which another regional union could be formed as a realistic counterweight.

Insisting that the right to apply for membership of the EU should be extended to nonEuropean states of course does not imply that any state is automatically entitled to join this enterprise, nor does it entail that the EU should strive to expand to the limit of N-n. What must be assessed, however, is the legitimacy of the EU's decision-making rules concerning enlargement. This task will be undertaken in section four. For now, we move on to discuss the nature of legitimate relations between the EU and non-member states. 


\section{Legitimacy of Relations with Non-Member States}

Our central question in this section is what kind of inclusion the EU owes non-member-states with which it has established relationships, or whom it affects through its actions. We distinguish three types of relations that ground claims to inclusion supported by three different principles. Relations that create negative externalities for populations in third countries call for the inclusion of externally affected interests through ex post justification or ex ante inclusion in a wider deliberative community; relations with associated states that lead to extensive incorporation of EU law into the domestic legal order of these countries give rise to claims for the inclusion of all subjected to coercion, which substantiates demands for protection of individual rights by EU law as well as opportunities to contest such law. Finally, as we will

discuss in section 4, associated states that meet fair criteria for accession have moral claims to be admitted based on a principle of including all membership stakeholders.

The principles of including all affected interests, all subjected to coercion and all membership stakeholders have been discussed mostly with regard to claims of individuals to citizenship in democratic states. We depart from this dominant approach in three ways. First, following Bauböck $(2015,2017)$, we claim that the principles are complementary rather than rival and support different ways of including different categories of persons. Second, the principles apply not merely to states, but also to sub-national and supra-national polities, which requires specifying their institutional implications for these contexts. Third, our concern in this paper is with the external borders and relations of the EU, so we need to consider how norms of democratic inclusion apply to states rather than to individuals.

The first type of EU external relations are with non-associated states. These can be morally structured either by reciprocity and an assumption of mutual benefit, or by strong 
asymmetries. International trade agreements, such as those that the EU has been negotiating with Canada and the US, exemplify the first kind. There are important normative questions involved concerning the impact of such agreements on decision-making powers of legislatures and judiciaries in the EU member states, on the one hand, and on third countries that are not involved in the agreement but may be indirectly affected by being excluded from most favourable conditions for trade, on the other hand. The second type concerns inherently asymmetric relations to states that are directly targeted by EU policies on development, international security or migration. Current EU relations to sub-Saharan and Middle Eastern countries are shaped by mixed goals of promoting peace, economic development and transition to or consolidation of democracy, but also by self-interested goals of stemming migration flows or securing market access for EU-based producers and extraction of natural resources.

In reciprocity-based relations, the interests of the states involved are generally assumed to be adequately represented. This assumption is warranted only if the governments involved meet minimum standards of democratic accountability towards their citizens. Such states' governments may still fail to adequately represent their citizens when negotiating international agreements, but this possibility does not create a duty of one side to step in and represent itself the interests of those who are not adequately represented by the other side. Doing so would be acting paternalistically without democratic mandate.

These are the contexts where the principle of including affected interests kicks in with full force. In our view, interests affected by EU external policies are not sufficient to generate stakes in membership of the union. However, external state and non-state actors have claims to be heard in EU level deliberations before policies are adopted that may have significant negative impact on populations in third countries.

The scope of the principle still needs to be qualified. Most theorists who defend it seem to have in mind an equal consideration of all affected interests through including their 
representatives in a deliberative community or deliberative demos (Cheneval 2011, Owen 2012). This strong interpretation is, however, implausible since it would include on an equal footing those whose interests are affected lightly or severely. It would also give equal weight to the voices of those whose being affected is a matter of "option luck", i.e. a risk that they have to bear and those who suffer a negative externality that they cannot foresee or protect themselves against (e.g. the impact of EU agricultural subsidies on farmers in developing countries).

We suggest that the principle of including affected interests creates thus a weak duty of ex post justification of policies towards all those whose interests are negatively affected as well as a much stronger duty of ex ante inclusion of those interests that are severely and "nonresponsibly" affected in the deliberation before a policy is adopted. In the former interpretation, the scope of the principle can be very wide and it could be satisfied by EU legislators demonstrating that they have properly taken into account how the policies and laws that they adopt could potentially affect non-EU states and populations or that they have vicariously taken into account the interests of citizens of non-democratic governments with whom the EU concludes agreements. This interpretation seems also adequate in relations where third countries are indirectly affected in a general way by forgoing the special benefits that EU cooperation with other states generates for these.

The second interpretation is more appropriate where EU policies specifically target third countries and where asymmetric power relations are involved, such as agreements on readmission of irregular migrants or trade agreements that force developing countries to open up their markets for EU agricultural producers. This stronger interpretation creates thus a deliberative community with narrower scope, which makes inclusion of externally affected interests not only normatively required but also practically feasible. Unlike the territorial political community undergirded by the citizenship stakeholder principle, this wider 
deliberative community is still a highly heterogeneous and fluctuating entity. It is "settled decision by decision rather than country by country" (Shapiro 2002: 244). In contrast to Shapiro's view, such a community cannot be conceived as a self-governing demos. In other words, the legitimacy of democratic decisions in such contexts depends on a dual requirement of including severely affected interests in the deliberation and of proper democratic authorization of the decision-makers by the citizens and member states of the union.

While the deliberative community is relatively amorphous, it still requires institutional expression if it is to provide democratic legitimacy to policy decisions. Such forms of institutionalisation may include international coordination bodies, access to courts and ombudsmen designed specifically to make the voices of those severely affected heard, and possibly even provisions for cross-border referendums on certain issues.

The second type of international relations of a union is with associated states. These are currently based on Art. 217 TFEU, according to which "The Union may conclude with one or more third countries or international organisations agreements establishing an association involving reciprocal rights and obligations, common action and special procedure.” The earliest association agreement was concluded with Turkey in 1963; currently there are 22 such agreements in force, including with far away countries such as South Africa. The largest number of states covered by these agreements are those included in the European Neighbourhood Policy (ENP) and the Stabilization and Association Process (SAP) in the Western Balkans. Some agreements, such as the one with Turkey, entailed from the start a prospect of future EU membership, while this was never considered for others.

This heterogeneity of association agreements makes it difficult to propose a general normative standard for evaluating them from a perspective of democratic inclusion. Some of these agreements do not go beyond the external relations of the first type that we have already discussed. We will therefore consider here only an associated status that is characterized by the 
following two elements: on the EU side there is a goal of shaping the political and legal regime of the country through the promulgation of the acquis communautaire and on the side of the associated country there is a corresponding readiness to transpose a significant number of EU legal norms into its domestic law.

Where these conditions are met, third countries and their populations are no longer merely externally affected by particular EU policies, but become in fact subjected to EUgenerated law and the institutions that back up the EU legal order. This is a context where the second principle of including all subject to coercion applies. The moral reasoning behind this principle is that governments that constrain the autonomy of individuals through subjecting them to a coercive legal order are legitimate only if they provide all such individuals with equal protection by the law and enable them to contest their subjection.

However, the citizens of associated states are obviously not fully subjected to the EU legal order. They remain primarily ruled by their own governments, but these latter are involved in a relation with the EU that is strongly 'asymmetric' (Eriksen and Fossum 2015). The EU determines its own laws and policies without any representation of associated states and then negotiates with these states which parts of that legal order they are willing to accept and implement as a condition for special relations with the EU in matters such as trade, free travel and participation in redistributive programmes.

Can such a relation be democratically legitimate? When answering this question, we need to consider that EU-associated states are sovereign members of the international community. This makes their status essentially different from that of associated non-sovereign territories, such as Puerto Rico or Guam, whose populations are US citizens without voting rights in US federal elections. The lack of full representation makes these associated statuses fundamentally illegitimate and acceptable only as transitional arrangements that lead either to independence or integration as a federal entity. The situation of associated EU states is different 
and prima facie legitimate because their nationals are not citizens of the EU and their own governments are free to accept or reject deeper integration into the EU legal order.

On our view, governments are required to protect the interests of all those whom they subject to coercive legislation by extending to them the protection of individual rights and opportunities for contestation. These claims are similar to the civil liberties and social rights of immigrants who do not yet qualify for or are not interested in naturalisation. However, for associated states that remain outside the territorial jurisdiction of the EU and its member states, inclusion that responds to partial subjection to EU law will have to be of a looser kind. It should still involve at a minimum access to EU territory through visa waiver or preferential immigration policies as well as access to the EU's court and ombudsman so that EU laws can be challenged also by non-citizens residing outside the EU's territory - in addition to including representatives of associated states in deliberations about any legislation that will become incorporated into the domestic law of these countries.

This leaves us with the question of decision-making procedures for the establishment of associate agreements in the first place. The current procedure in Art. 218 TFEU envisages a decision by qualified majority in the Council and consent of the EP. Unanimity is required only if the agreement includes matters on which the Council has to decide unanimously. From a normative perspective, we believe that this procedure is defensible, since an association agreement does not include the third country and its citizens in the EU demos. The constitutive demoi of the EU have therefore no legitimate interest to decide independently of each other on whether to accept an associated third country. Instead, the EU legislator representing both member states in the Council and EU citizens in the EP should have the power to conclude such agreements. The Dutch consultative referendum of 6 April 2016 on the EU association agreement with Ukraine was, therefore, in our view problematic. First, association agreements should be decided by the EU legislator. Second, generalizing plebiscitary ratification or 
rejection of association agreements in each member state would minimize the chances of any such agreement ever being adopted.

\section{Moral duties and procedural legitimacy in accession}

For associated states that meet the accession criteria, this kind of subjection to EU law gives rise to a third kind of inclusion claim. Just as immigrants acquire after some time of residence a claim to citizenship, so associated countries acquire a claim to EU membership if they have comprehensively transposed EU law or have been integrated in its open internal borders and free movement regimes. The 'citizenship stakeholder' principle undergirds this claim. It states that those and only those individuals have a claim to membership and participation in political decision-making 'whose individual autonomy and well-being is linked to the collective selfgovernment and flourishing of a particular polity’ (Bauböck 2015: 825). The principle implies that membership admission rules must take into account not only the strength of ties between individuals and polities but also the conditions under which both can be self-governing (Bauböck 2017).

But how should we think about inclusion claims of new member states rather than of individual citizens? On the one hand, states have a moral claim to accession if they have accepted to be comprehensively bound by EU law and if they meet the fair accession criteria discussed in section 2. The reason is that after a certain time and degree of integration into the EU legal order, the citizens of such states can retrieve democratic control over EU laws only by exercising it jointly with the citizens of the current member states. These claims to accession correspond to a moral duty of current member states to accept such candidates for accession. On the other hand, the self-government rights of both an accession candidate and the current 
member states would be violated if accession were automatic and the citizens of these countries could not decide. This is what makes the process of admission of new states to a union fundamentally different from that of newly born individuals in a democratic state. In the latter context, transgenerational self-government requires that citizenship is acquired automatically at birth, in the former, the government of the accession country must get the consent of its citizens for this fundamental change in the country's external relations and the citizens of the current member states must be seen to have agreed to admission. The tension between these two implications of a stakeholder principle applied to EU accession means that the moral claims of accession countries do not translate into rights and that current member states' moral duties to admit do not translate into political obligations.

In the EU context, the procedural condition for the consent of current member states to accession is unanimity. Because unanimity among all member state governments is de iure required for a country to accede to the EU, even after that country has satisfactorily met all accession criteria, unanimity in the European Council is also de facto required in order to allow the commencement of accession negotiations with the applicant country. In consequence, one state acting alone has the capacity to block the accession application and eventual accession of any and all countries. This situation has the potential to be pernicious, as member states may use their veto to block the accession of non-member states for reasons that have little to do with the latter's potential eligibility for membership or the EU's institutional readiness. Despite the possibility for one or more countries to abuse their power to decide on the fate of a non-member state, is there a sound normative basis for the unanimity requirement in cases of accession?

Two views are possible here. A normative perspective focused on the most just outcome would suggest that once member states set out fair criteria of accession to the Union, any country that successfully fulfilled these criteria would be automatically entitled to join without further approval by member states. While states would be deliberatively engaged in the 
accession process, raising objections when they believe that the criteria are being applied too loosely, the ability of any particular state or small group of states to block a valid accession application would be curtailed. We believe that the stakeholder principles' emphasis on collective self-government chimes better with a second view based on the 'statespeoples sovereignty principle' defended by demoicratic scholars. It insists that no member state should be subjected to the will of any others, requiring that EU membership be entirely voluntary and that unanimity is the decision rule in making primary law (Nicolaïdis 2013; Bellamy 2013; Cheneval and Schimmelfennig 2013; Lacey 2016). Although these authors are not explicit on the point, to the extent that the statespeoples sovereignty principle prioritises political inputs of self-determination, rather than political outputs of justice, this principle would seem to support the unanimity requirement in decisions on accession applicants.

Let us investigate the issue by first dealing with the most difficult case, namely the right for states to unanimously deny the accession of closely associated member states who are capable and willing to meet all of the accession criteria. What makes this a hard case is our earlier contention that, at some point, the subjection of associated states to EU laws becomes so comprehensive that they acquire a moral claim to membership in order to restore their damaged capacity to govern themselves through joining the union and shaping its laws from a position of equality with the existing member states and their citizens. If it can be demonstrated that the unanimity requirement is defensible even in these cases, despite the associated states' moral claim, then it will by extension also validly apply to applicant states who have less significant ties to the EU.

In discussing the proximity principle, we suggested that a key feature of political integration is the pursuit of open-ended collective projects that are ideally determined by a fair democratic process. Accepting an associated state for membership of the Union requires a change in the former's status such that it is a) considered a default partner in future collective 
projects (notwithstanding possibilities for differentiated integration) and b) fully entitled to participate in the democratic process that would determine the nature of these projects. The value of self-determination expressed by the statespeoples sovereignty principle implies that individual member states have the right to a final say concerning with whom they pool their sovereignty. The rationale is that this kind of decision will influence the nature of future political projects and thereby play a substantial role in determining the destiny of the Union and each member state therein. Perhaps most important in this regard is the necessary reconfiguration of EU institutions, such as the Council and European Parliament, to accommodate for the equal representation of new members. Not only will a new set of values and interests be brought to each institution, the ability of other states to make their voice heard will be diminished as new voices are added. Being forced to accept this state of affairs through an automatic bureaucratic process, or the majority decision of other member states, would be a fundamental breach of national self-determination.

A further argument for maintaining unanimity invokes the value of stability. While the Commission (2006) was initially keen to emphasise institutional and budgetary issues when referring to the EU's integration capacity, Lisbon Treaty reforms and the relative success at institutionally integrating new member states in recent waves of enlargement has largely dispelled the idea that there may be insurmountable obstacles of this kind to future enlargement. Notwithstanding the tendency of EU member states to pursue their own long-term economic and geo-political interests in previous rounds of enlargement (Moravcsik and Vachudova 2003), scholars now highlight public support as the primary potential limitation to the EU's contemporary integration capacity (Dimitrova and Kortenska 2017). Precisely because of the much denser social and political interactions between current and new member states, without the public willingness to embrace or at least tolerate these closer interactions, the potential for destabilisation is significant. Not only may there be tensions between citizens of new member 
states and citizens of member states who opposed enlargement, but support for the EU in the latter is also likely to decline, making further enlargements or other forms of integration more difficult to achieve.

In light of this consideration, maintaining the unanimity requirement need not be seen as just giving expression to a principle of self-determination. Even if member states were willing to allow enlargement decisions to rest on a majority vote between them, unanimous decision-making may be still desirable as a way of ensuring that public support for a particular enlargement is sufficiently widespread so as not to jeopardise the stability or policy goals of the Union. This may at first seem like a merely prudential justification for the unanimity requirement. However, what gives this justification a further normative basis is the primary duty of the EU to fulfil its Treaty obligations - a task which would be made much more difficult if enlargement was undertaken without the required level of public support in all member states.

On the basis of these arguments, we can say that being comprehensively subject to coercion by EU law and taking a democratic decision in favour of accession provides candidate states with a moral claim for membership, but that this does not trump the right of any existing member state to have final decision-making power over whether or not that claim is satisfied.

Affirming the priority of the statespeoples' sovereignty principle over claims of justice in admission, however, does not mean that procedures must give expression to this principle only. A higher-order normative perspective must aim to reconcile the values of justice and selfdetermination insofar as possible. For example, requiring that accession decisions must be ratified by majorities of citizens in separate referendums in each member state would amount to a needlessly extreme interpretation of the unanimity principle by maximizing the veto power of individual member states and the opportunities of populist parties to block enlargement. Instead, the tension between self-determination and justice ought to be reduced through 'democratic iterations' (Benhabib 2004), i.e. by securing throughout the process not only the 
commitment of the candidate state to meet the accession conditions but also a political consensus on future accession among the current member states and their citizens. Regarding such mutual commitments as an important part of the process would also help to mitigate the inevitable asymmetry of the accession relation.

This normative position becomes even more weighty in light of recent research on enlargement, which raises the pragmatic concern that the EU's ability to promote reform in applicant states is unduly hampered by the failure of member states to openly discuss future enlargement as a live possibility (Börzel, Dimitrova and Schimmelfennig 2017). In other words, precisely because the ability of candidate countries to meet the accession criteria is dependent on the credible commitments of the EU to future enlargement, it is incumbent on the EU to assist candidate countries to move beyond the limbo of their candidate status by openly building consensus on an enlargement agenda.

Let us conclude this section by considering how negative outcomes of decisions on accession create democratic legitimacy deficits and how these could be reduced.

The first scenario is one where the EU rejects candidacy status for an associated country that has taken great efforts to implement the EU legal order and has accepted to implement future EU legislation. In this case, the citizens of this country will be subjected to a legal order in whose making they do not have a say and whose institutions cannot protect them in the same way as EU citizens. Their situation is analogous to that of long-term resident immigrants who apply for naturalisation and meet the conditions but are rejected by a discretionary decision. In the second scenario, the EU accepts the candidacy status of such a country but its government or citizens themselves reject EU membership, in which case the cause of the legitimacy deficit becomes an internal one in that country. Through treaties with the EU requiring unilateral transposition of a comprehensive bundle of laws, such states are significantly less selfgoverning than they would be as either fully independent states or as member states of the EU, 
but their legislators or citizens have freely chosen this democratic predicament. This is the current situation in Switzerland, Iceland, Liechtenstein and Norway (cf. Eriksen and Fossum 2015). It would, paradoxically, also become that of the UK after a "soft Brexit" in which the UK subjects itself to binding EU law in various areas without being represented in the making of such law.

Neither of these two potential representation deficits implies that associated status is inherently illegitimate and unstable. If either the EU has compelling reasons for not accepting an associated country as a future member state or if an associated country decides that it does not want to join the EU, then this country could be offered a form of association that leaves it free to opt in or out of new EU legislation, which would avoid involuntary subjection to new EU law over which the associated country has no control.

\section{Conclusions: Nationalist Limitations to European Borders}

In this paper, we have discussed substantive normative issues concerning European enlargement and relations with third-countries, as well as more procedural issues pertaining to the appropriate decision-making rules for accepting states as new members or associates. When it came to the limits of European enlargement, we found no normative basis for restricting Europe's final frontiers to "European states". However, in exploring the criteria for limiting European expansion, we arrived at several nuances. First, it is legitimate to restrict membership to liberal democratic states. Second, the proximity principle establishes a priority of enlargement to neighbours. Third, although there is a trade-off between deeper integration and numbers of member states, it can be mitigated by differentiated integration or constitutional tinkering. Fourth, there should be a numeric limit of N-n for EU enlargement, with $\mathrm{n}$ being the smallest number of states that could credibly form a counter-weight regional union. 
In discussing the EU's external relations, we distinguished between EU membership grounded in the stakeholder principle and other forms of inclusion based on the principles of including affected interests and all subjected to coercion. The affected interests principle was found relevant in two main cases. First, mutually beneficial agreements with third countries require ex post justification towards excluded third countries whose interests are affected. Second, asymmetric relations of power with third countries require ex ante inclusion in a deliberative community. The principle of including all subjected to coercion is most relevant to those associate agreements where third countries are expected to transpose large parts of the acquis into national law. Such states must not only have access to contestatory institutions, like courts, but also have a moral claim to accession given the democratic deficit that exists in being subject to laws in the making of which making they have no say.

In the penultimate section, we identified a tension between just outcomes and the demoi-cratic commitment to member state self-determination. Although we believe that any institutional design should seek to reconcile the normative demands of justice and selfdetermination insofar as possible, we advocated that normative priority be granted to the latter in determining decision-making procedures for accession of new member states. This justifies the current practice of unanimity decisions on accession. The existing supermajority procedure to establish associate agreements was also deemed to be valid since, unlike accession to full membership, such agreements do not change the shape of the polity or pool sovereignty.

Precisely because we have given precedence to procedural means of self-determination over concerns of substantive justice, the strength of nationalist sentiment will constitute the central obstacles to fulfilling our prescriptions in this paper. Most importantly, nationalists are already concerned about the threat to national self-determination and identity that an organisation like the EU poses to its members because of the manner in which this political system opens up the nation-state to more immigration while simultaneously requiring shared 
rule with elites from different national backgrounds and political traditions. Should the EU be open to expansion beyond Europe or thick association agreements involving free movement, the fear of greater immigration and the need to share rule with ever more diverse elites will be even greater. To use ANONYMOUS AUTHOR's language in his paper for this volume, restricting EU membership to "European" states provides a minimal degree of ontological security at the European level for nationalists who already fear that their ontological security at the national level is to some degree threatened by the EU itself. As we saw in the case of a Dutch referendum on deeper ties with Ukraine, these fears can even pose obstacles to the creation of association agreements.

One of our arguments for maintaining the unanimity requirement in cases of enlargement suggested that this condition would help to ensure widespread public support for enlargement across the Union, and thus ensure stability. When political integration is pursued in the context of a permissive consensus, such that national and European elites drive forward integration without attaining direct public support from citizens, this effect may be limited. Certainly, one of the important narrative resources for those domestic politicians advocating a British withdrawal from the EU was the public rejection of migration brought about by the Eastern enlargement. The British governments in power during these accession periods were enthusiastic about Eastern enlargement, but had not secured sufficient public support for it. In a voluntary union of states, where withdrawal is now established as a realistic possibility, it is futile to overrule the citizens of any member states when it comes to accession decisions. The constraining dissensus towards European integration that has emerged in the last years is a definite sign that any further European integration, whether it concerns deepening or widening, must be founded on a new 'active consensus' that directly engages the wills of the several peoples of Europe. It is at least in part the task of national and European elites to ensure that the moral claims of non-member states form an important part of the public debates. 


\section{References}

Abizadeh, Arash. 2012. "On the Demos and its Kin: Nationalism, Democracy, and the Boundary Problem." American Political Science Review 106 (4):867-882.

Bauböck, Rainer. 2015. "Morphing the Demos into the right shape. Normative principles for enfranchising resident aliens and expatriate citizens." Democratization 22 (5):820-839.

Bauböck, Rainer (2017) Democratic Inclusion. Rainer Bauböck in Dialogue. Manchester: Manchester University Press, forthcoming.

Bellamy, Richard. 2013. “An Ever Closer Union Among the Peoples of Europe”: Republican Intergovernmentalism and Demoicratic Representation within the EU. Journal of European Integration, 35 (5): 419-516.

Benhabib, Seyla 2004. The Rights of Others. Cambridge, UK: Cambridge University Press.

Council of Europe. 1992. Parliamentary Assembly, Information Report on the Enlargement of the Council of Europe. Doc. 6629, 16 June.

Börzel, Tanja A. Antoaneta Dimitrova and Frank Schimmelfennig. European Union Enlargement and Integration Capacity: Concepts, Findings and Policy Implications. Journal of European Public Policy, 24 (2): 157-76. 
Cheneval, Francis. 2011. The Government of the Peoples: On the Idea and Principles of Multilateral Democracy. New York: Palgrave Macmillan.

Cheneval, Francis and Schimmelfennig, Frank. 2013. The Case for Demoi-cracy in the European Union. Journal of Common Market Studies, 51 (2), pp. 334-50.

Dimitrova, Antoaneta and Elitsa Kortenska. 2017. What Do Citizens Want? And Why Does it Matter? Discourses Among Citizens as Opportunities and Constraints for EU Enlargement. Journal of European Public Policy, 24 (2): 259-77.

Eriksen, Erik O. and John Erik Fossum (eds.). 2015. The European Union's Non-Members. Independence under Hegemony. London: Routledge.

European Commission. 2006. Enlargement Strategy and Main Challenges 2006-2007 Including Annexed Special Report on the EU's Capacity to Integrate New Members.

Grimm, Dieter. 2015. The Democratic Costs of Constitutionalisation: The European Case. European Law Journal, 21 (4): 460-73.

Karakas, Cemal. 2013. EU-Turkey Integration without Full Membership or Membership without Full Integration? A Conceptual Framework for Accession Alternatives. Journal of Common Market Studies, 51 (6): 1057-73.

Kelemen, Daniel R., Anand Menon and Jonathan Slapin. 2014. Wider and Deeper? Enlargment and Integration in the European Union. Journal of European Public Policy, 21 (5): 647-663. 
Kymlicka, Will. 2001. Politics in the Vernacular: Nationalism, Multiculturalism, and Citizenship. Oxford: Oxford University Press.

Lacey, Joseph. 2016. 'Conceptually Mapping the European Union: A Demoi-cratic Analysis', Journal of European Integration, Vol. 38 No. 1, pp. 61-77.

Lacey, Joseph. 2017. Centripetal Democracy: Democratic Legitimacy and Political Identity in Belgium, Switzerland and the European Union. Oxford: Oxford University Press.

Miller, David 1995. On Nationality. Oxford: Oxford University Press.

Moravcsik, Andrew and Milada Anna Vaduchova. 2003. National Interests, State Power and EU Enlargement. European Politics and Society, 17 (1): $42-57$.

Nicolaïdis, Kalypso. 2013. European Demoi-cracy and its Crisis. Journal of Common Market Studies, 51 (2), pp. 351-69.

Nicolaïdis, Kalypso. 2014. Europe's Ends. The Meanings of Europe: Changes and Exchanges of a Contested Concept, edited by Claudia Wiesner and Meike Schmidt-Gleim. London: Routledge.

Owen, David. 2012. "Constituting the polity, constituting the demos: on the place of the all affected interests principle in democratic theory and in resolving the democratic boundary problem." Ethics and Global Affairs 5 (3):129-152. 
Scharpf, Fritz W. 2015. After the Crash: A Perspective on Multilevel European Democracy. European Law Journal, 21 (3): 384-405.

Shapiro, Ian. 2002. "The State of Democratic Theory." In Political Science. State of the Discipline edited by Ira Katznelson and Helen V. Milner, 235-265. New York: W. W. Norton.

Sjursen, Helene. 2002. Why Expand? The Question of Justification and Legitimacy in the EU's Enlargement Policy. Journal of Common Market Studies, 40 (3): 491-513.

Waldron, Jeremy. 2011. The Principle of Proximity. NELLCO Legal Scholarship Repository. http://lsr.nellco.org/cgi/viewcontent.cgi?article=1256\&context=nyu_plltwp 